\title{
Biological evaluation and determination of the absolute configuration of chloromonilicin, a strong antimicrobial metabolite isolated from Alternaria sonchi
}

\author{
Alessio Cimmino ${ }^{1}$, Gennaro Pescitelli ${ }^{2}$, Alexander Berestetskiy ${ }^{3}$, Anna Dalinova ${ }^{3}$, Denis Krivorotov ${ }^{4}$, \\ Angela Tuzi ${ }^{1}$ and Antonio Evidente ${ }^{1}$
}

Chloromonilicin was isolated for the first time from Alternaria sonchi, a mycoherbicide proposed for the control of the noxious weed Sonchus arvensis. The already known alternethanoxins A and B and the three recently isolated phytotoxic polycyclic ethanones named alternethanoxins C-E were also isolated from the same source. Chloromonilicin was identified by spectroscopic data (essentially one-dimensional NMR, 2-dimensional NMR and high-resolution ESI-MS) and its structure was confirmed by single X-ray analysis, which also allowed the assignment of the absolute configuration. This latter was independently confirmed by electronic $\mathrm{CD}$ calculations. When chloromonilicin was tested for its antimicrobial activity, it was active at concentrations $0.5-1 \mu \mathrm{g}$ per disc against four bacterial species and a yeast fungus. The compound inhibited conidial germination of four plant pathogens at concentration of $1-10 \mu \mathrm{g} \mathrm{m}^{-1}$. No phytotoxic activity of this antibiotic by leaf-disc puncture bioassay was detected. The Journal of Antibiotics (2016) 69, 9-14; doi:10.1038/ja.2015.74; published online 15 July 2015

\section{INTRODUCTION}

Sonchus arvensis L., commonly called perennial sow thistle, is considered to be an important weed in Europe and North America. It infests many habitats such as cultivated fields, roadsides, pastures and lawns with consequent heavy economic losses. Most of the herbicides recommended for the control of S. arvensis are generally restricted to only a few active ingredients that tend to have low selectivity, especially for dicots crops. ${ }^{1}$ Natural enemies of weeds such as plant pathogens could be used for weed biocontrol as an ecofriendly and quite selective support of crop protection measures. ${ }^{2}$ Two plant pathogenic fungi, Alternaria sonchi J.J. Davis and Phoma exigua Desm. var. exigua have been considered as potential mycoherbicides for $S$. arvensis. ${ }^{3}$

It is well known that plant pathogens such as fungi and bacteria produce numerous secondary metabolites including virulence and defense factors. Phytotoxins can be used as natural herbicides or models for the synthesis of herbicidal biorationals. Metabolites with different types of biological activity may have positive or negative side effects on macroorganisms and soil microflora. ${ }^{4}$ For this reason, the chemistry of weed biocontrol agents should be studied as deeply as possible. For example, Ph. exigua var. exigua was found to produce numerous cytotoxic cytochalasins. The presence of these compounds could be a restriction for a practical application of the fungus as a bioherbicide. $^{5}$
Extracts of $A$. sonchi obtained from solid cultures of the fungus were shown to have a phytotoxic and an antimicrobial activity. ${ }^{6}$ Five polycyclic ethanones (phytotoxins and weak antimicrobials), namely, alternethanoxins A-E were isolated from the fungal solid culture. ${ }^{7,8}$ Alternethanoxins $\mathrm{A}$ and $\mathrm{B}$, as well as the dimethyl derivative of alternethanoxin A, showed cytostatic growth inhibitory effect when evaluated on six cell lines for their anticancer activity. ${ }^{9}$ These studies demonstrated that $A$. sonchi is a rich source of new and interesting metabolites.

Further investigation of the organic extract of A. sonchi solid culture allowed the isolation of a known but poorly characterized antimicrobial metabolite belonging to xanthone group. This manuscript reports the isolation of chloromonilicin (1, Figure 1) from the solid culture of A. sonchi as the first finding of this metabolite in Alternaria fungi. Chloromonilicin, which represents the main fungal metabolite, appeared to be non-phytotoxic but showed a strong antimicrobial activity. The potential of $A$. sonchi as a mycoherbicide and its environmental safety is discussed.

\section{MATERIALS AND METHODS}

Chemistry

Melting points were measured on an Axioskop Zeiss miscroscope (Zeiss, Jena, Germany) coupled with a Mettler FP90 hot (Mettler, Greifensee, Switzerland); optical rotation was measured on a Jasco P-1010 digital polarimeter (JASCO, Tokyo, Japan); and electronic CD (ECD) spectra were recorded on a JASCO

\footnotetext{
${ }^{1}$ Dipartimento di Scienze Chimiche, Università di Napoli Federico II, Complesso Universitario Monte S. Angelo, Napoli, Italy; ${ }^{2}$ Dipartimento di Chimica e Chimica Industriale, Università di Pisa, Pisa, Italy; ${ }^{3}$ Department of Phytotoxicology and Biotechnology, All-Russian Institute of Plant Protection, Federal Agency of Scientific Organizations, Pushkin, Saint Petersburg, Russian Federation and ${ }^{4}$ Department of Chemical Modelling, Research Institute of Hygiene, Occupational Pathology and Human Ecology, Federal Medical Biological Agency, Saint-Petersburg, Russian Federation

Correspondence: Professor A Evidente, Dipartimento di Scienze Chimiche, Università di Napoli Fedreico II, Complesso Universitario Monte S. Angelo, Via Cintia 4, Napoli 80126, Italy. E-mail: evidente@unina.it

Received 24 November 2014; revised 3 March 2015; accepted 8 June 2015; published online 15 July 2015
} 
<smiles>CC(=O)C1OC(=O)C=C(Cl)c2oc3cc(C)cc(O)c3c(=O)c21</smiles>

1<smiles>CC(=O)c1ccc(Cl)c2oc3cc(C)cc(O)c3c(=O)c12</smiles>

2

Figure 1 Structures of chloromonilicin (1) and its biosynthetic precursor 4-chloropinselin (2).

Table $1{ }^{1} \mathrm{H}(400 \mathrm{MHz}),{ }^{13} \mathrm{C}$ NMR $(100 \mathrm{MHz})$ and HMBC data of chloromonilicin in $\mathrm{CD}_{3} \mathrm{COCD}_{3}(1)^{\mathrm{a}, \mathrm{b}}$

\begin{tabular}{lccc}
\hline Position & $\delta_{\mathrm{C}}{ }^{c}(m)$ & $\delta_{\mathrm{H}}(\mathrm{m}, \mathrm{J})$ & $\mathrm{HMBC}$ \\
\hline 1 & $169.2(\mathrm{~s})$ & & $\mathrm{OMe}$ \\
2 & $68.7(\mathrm{~d})$ & $6.48(1 \mathrm{H}, \mathrm{s})$ & $\mathrm{OMe}$ \\
3 & $120.4(\mathrm{~s})$ & & $\mathrm{H}-9, \mathrm{H}-7, \mathrm{H}-2$ \\
4 & $181.2(\mathrm{~s})$ & & $\mathrm{H}-9, \mathrm{H}-7$ \\
5 & $109.8(\mathrm{~s})$ & & $\mathrm{H}-9, \mathrm{C}-\mathrm{CH}_{3}$ \\
6 & $158.3(\mathrm{~s})$ & & \\
7 & $110.1(\mathrm{~d})$ & $7.02\left(1 \mathrm{H}, \mathrm{s}^{\mathrm{d}}\right)$ & $\mathrm{H}-7, \mathrm{C}-\mathrm{CH}_{3}$ \\
8 & $152.0(\mathrm{~s})$ & & $\mathrm{H}-2$ \\
9 & $115.3(\mathrm{~d})$ & $6.81\left(1 \mathrm{H}, \mathrm{s}^{\mathrm{d}}\right)$ & \\
10 & $162.4(\mathrm{~s})^{\mathrm{e}}$ & & \\
11 & $162.1(\mathrm{~s})^{\mathrm{e}}$ & & \\
12 & $136.4(\mathrm{~s})$ & & \\
13 & $132.0(\mathrm{~d})$ & $7.16(1 \mathrm{H}, \mathrm{s})$ & \\
14 & $163.5(\mathrm{~s})$ & & \\
$\mathrm{C}-\mathrm{CH}_{3}$ & $23.6(\mathrm{q})$ & $2.29\left(3 \mathrm{H}, \mathrm{s}^{\mathrm{d}}\right)$ & \\
$\mathrm{O}-\mathrm{CH}_{3}$ & $55.2(\mathrm{q})$ & $3.83(3 \mathrm{H}, \mathrm{s})$ & \\
$\mathrm{OH}$ & & $11.82(1 \mathrm{H}, \mathrm{s})$ & \\
\hline
\end{tabular}

${ }^{a}$ Chemical shifts are in $\delta$ values (p.p.m.) from TMS.

${ }^{b} 2 \mathrm{D}{ }^{1} \mathrm{H},{ }^{1} \mathrm{H}(\mathrm{COSY})$ and ${ }^{13} \mathrm{C}, 1 \mathrm{H}(\mathrm{HMQC}) \mathrm{NMR}$ experiments confirmed the correlations of all the protons and the corresponding carbons.

cMultiplicities were assigned with DEPT.

dThe protons $\mathrm{H}-7$ and $\mathrm{H}-9$ were themselves and both coupled with $\mathrm{C}-\mathrm{CH}_{3}$ probably with

$\mathrm{J}<1 \mathrm{~Hz}$.

eThese two carbons are previously reported as an overlapped signal. ${ }^{6}$

J-815 spectropolarimeter in acetonitrile. IR spectrum was recorded as deposit glass film on a Thermo Electron Corporation Nicolet 5700 FT-IR spectrometer (Thermo Scientific, WI, USA) and UV spectra were measured in $\mathrm{MeOH}$ and acetonitrile on a Jasco V-530 spectrophotometer. ${ }^{1} \mathrm{H}$ and ${ }^{13} \mathrm{C}$ NMR spectra were recorded at 400 and $100 \mathrm{MHz}$, respectively, in $\mathrm{CD}_{3} \mathrm{COCD}_{3}$ on a Bruker AVANCE III $400 \mathrm{MHz}$ spectrometer (BRUKER, Karlsruhe, Germany). The same solvent was used as internal standard. COSY-45, HMQC, HMBC and ROESY experiments ${ }^{10}$ were performed using standard Bruker pulse sequences. High-resolution (HR) ESI-MS spectra were recorded on Agilent 6530 Q-TOF LC/MC spectrometer (Agilent, Moscow, Russia). Analytical normal-phase TLC was performed on silica gel plates (Silica gel $60 \mathrm{~F}_{254}, 0.25 \mathrm{~mm}$, Merck, Darmstadt, Germany) using a mixture of $n$-hexane-EtOAc (6:4) as eluent. The spots were visualized by exposure to UV radiation $(254 \mathrm{~nm})$, or by spraying first with $10 \% \mathrm{H}_{2} \mathrm{SO}_{4}$ in $\mathrm{MeOH}$ and then with $5 \%$ phosphomolybdic acid in $\mathrm{EtOH}$, followed by heating at $110^{\circ} \mathrm{C}$ for $10 \mathrm{~min}$. Low-pressure column chromatography was performed on silica gel columns (Merck, Kieselgel 60, $0.063-0.200 \mathrm{~mm}$ ). Medium-pressure chromatography was performed with Sepacore system (Büchi, Flawil, Switzerland) on Puriflash prepacked normalphase column (Silica HP, $15 \mu \mathrm{m}, 12 \mathrm{G}$, Interchim, Montluçon, France) using $n$ hexane-EtOAc step gradient elution. Semi-preparative HPLC was carried out with a HPLC system (Breeze, Waters, Milford, MA, USA) equipped with dualwave UV-vis detector, degasser and column thermostat, on a SymmetryPrep
C18 $(7.8 \times 150 \mathrm{~mm}, 7 \mu \mathrm{m})$ column (Waters) using $\mathrm{MeCN}-0.1 \%$ formic acid (6:4) as eluent under the following conditions: detection wavelengths 254 and $280 \mathrm{~nm}$, flow rate $5 \mathrm{ml} \mathrm{min}^{-1}$, temperature $30^{\circ} \mathrm{C}$.

Fungal strain and extraction and purification of chloromonilicin (1) The strain (S-102) of A. sonchi used in this study was deposited in the collection of All-Russian Research Institute of Plant Protection (Pushkin, SaintPetersburg, Russia). The fungus was grown on autoclaved pearl barley and the solid culture was extracted with acetone-water (50:50) according to the procedure previously reported by Evidente et al. ${ }^{7}$ After evaporation of the acetone-water phase, the residue was passed through a column containing $20 \mathrm{~g}$ of Diaion HP-20 (Sigma-Aldrich, Moscow, Russia), and the column was washed with water, $\mathrm{MeOH}, \mathrm{EtOAc}$ and $\mathrm{CH}_{2} \mathrm{Cl}_{2}$. The dry residue $(5.2 \mathrm{~g})$ of the $\mathrm{MeOH}$ extract demonstrated both phytotoxic and antimicrobial activity and was fractionated with column chromatography on silica gel with mixtures of $\mathrm{CH}_{2} \mathrm{Cl}_{2}-\mathrm{MeOH}$ (100:0, 95:5, 90:10 and 80:20) to obtain four fractions. The fraction $\mathrm{B}(3.3 \mathrm{~g})$ showed both phytotoxic and antimicrobial activity and was further separated on silica gel with $\mathrm{CH}_{2} \mathrm{Cl}_{2}-$ iso- $\mathrm{PrOH}$ into five fractions. Fraction B2 $(80 \mathrm{mg})$ possessed strong antimicrobial activity. Compound 1 $\left(R_{\mathrm{f}} 0.36\right.$ in $n$-hexane-EtOAc 6:4) was purified from this latter fraction by medium-pressure chromatography on silica gel using step gradient of $n$-hexane-EtOAc and finally by semi-preparative HPLC according to the conditions reported above (21 mg; Rt $5.0 \mathrm{~min})$.

\section{Chloromonilicin (1)}

Melting point $170-171^{\circ} \mathrm{C} ;[\alpha]^{25} \mathrm{D}+202\left(c 0.6 \mathrm{CHCl}_{3}\right)$; IR $\nu_{\max }: 3481,1746$, $1726,1646,1615,1594$ and $1269 \mathrm{~cm}^{-1}$; UV $\lambda^{\mathrm{MeCN}_{\max } \mathrm{nm}(\varepsilon) 279(18,200)}$ 205 (22,500); $\mathrm{CD} \lambda^{\mathrm{MeCN}_{\max } \mathrm{nm}(\Delta \varepsilon)} 308(+9.52) 279(+12.8) 253(0)$ $242(-16.0) 234(-11.3) 217(-31.8) 207$ (0) 199 (+27.3) (lit. 10: m.p. $169.5-170.5^{\circ} \mathrm{C} ;[\alpha]_{\mathrm{D}}\left(\right.$ c $\left.\left.0.4, \mathrm{CHCl}_{3}\right)+212\right) ; \mathrm{UV} \lambda^{\mathrm{MeOH}} \max \mathrm{nm}(\varepsilon) 276$ (20,000); IR $\nu^{\mathrm{CHCl}_{3}} \operatorname{max~cm}{ }^{-1} 3040,1755,1733,1655,1620$ and 1602); ${ }^{1} \mathrm{H}$ and ${ }^{13} \mathrm{C}$ NMR: Table 1; ESI-MS (+) $\mathrm{m} / \mathrm{z}$ : 723.0232 [calcd for $\mathrm{C}_{32} \mathrm{H}_{22} \mathrm{Cl}_{2} \mathrm{NaO}_{14}$ 723.0284, $2 \mathrm{M}+\mathrm{Na}]^{+} ; 388.9805$ [calcd for $\mathrm{C}_{16} \mathrm{H}_{11} \mathrm{ClKO}_{7}$ 388.9830, M+K] $]^{+}$, 373.0065 [calcd for $\left.\mathrm{C}_{16} \mathrm{H}_{11} \mathrm{ClNaO}_{7} 373.0091, \mathrm{M}+\mathrm{Na}\right]^{+}$.

\section{Crystal structure determination of chloromonilicin (1)}

Yellow block-shaped single crystals were obtained at ambient temperature by slow evaporation of a $\mathrm{C}_{6} \mathrm{H}_{6} / \mathrm{MeOH}$ (3:1) solution. X-ray data collection was performed at $298 \mathrm{~K}$ on a Bruker-Nonius Kappa charge-coupled device diffractometer equipped with graphite-monochromated Mo-K $\alpha$ radiation ( $\lambda=0.71073 \AA$, charge-coupled device rotation images, thick slices, $\varphi$ and $\omega$ scans to fill the asymmetric unit). Cell parameters were obtained from a leastsquares fit of the $\theta$ angles of 455 reflections in the range $6.663^{\circ} \leqslant \theta \leqslant 16.702^{\circ}$. A semi-empirical absorption correction (multiscan, SADABS, Bruker, WI, USA) was applied. The structure was solved by direct methods (SIR97 package) 11 and refined by the full matrix least-squares method on $F^{2}$ against all independent measured reflections (SHELXL program of SHELX97 package). ${ }^{12}$ All $\mathrm{H}$ atoms were placed in calculated positions and allowed to ride on carrier atoms $\left(\mathrm{C}-\mathrm{H}\right.$ in the range $0.95-1.00 \AA ; U=1.2 \mathrm{U}_{\text {iso }}$ or 1.5 for methyl $\left.\mathrm{C}\right)$ except for the position of the hydroxyl $\mathrm{H}$ atom of the two independent molecules found in the asymmetric unit, which was determined from a 
difference Fourier map and refined according to a riding model. 22005 intensities were collected in the range $2.96^{\circ} \leqslant \theta \leqslant 27.02^{\circ}$, 6302 independent reflections and 443 parameters. Thanks to the presence of the strong anomalous scatterer (chlorine atom), the absolute configuration $(S)$ at $\mathrm{C} 2$ atom of both the two independent molecules was established by anomalous dispersion effects obtained in diffraction measurements on the crystal. (Flack's parameter ${ }^{13}$ was 0.06(10) from 3035 Friedel pairs). The final refinement converged to $R_{1}=0.0638$ for 3775 observed reflections having $[I>2 \sigma(I)]$ and $w R_{2}=0.1603$ for all data. Final minimum and maximum residual electronic density was -0.211 and 0.236 e $\AA^{-3}$. Crystal data: formula $\mathrm{C}_{16} \mathrm{H}_{11} \mathrm{ClO}_{7}$, formula weight $350.70 \mathrm{~g} \mathrm{~mol}^{-1}$, hexagonal $\mathrm{P}_{5}, a=7.9450(5) \AA, c=81.655(2) \AA, \gamma=120.0^{\circ}$, $V=4463.8(4) \AA^{3}$ and $Z=12$.

CCDC-1031657 contains the supplementary crystallographic data for this paper. These data can be obtained free of charge from The Cambridge Crystallographic Data Centre via www.ccdc.cam.ac.uk/data_request/cif.

\section{Computational section}

Merck molecular force field and density functional theory (DFT) calculations were run with Spartan'10 (Wavefunction, Irvine, CA, USA 2010), with standard parameters and convergence criteria. Time-dependent DFT (TDDFT) calculations were run with Gaussian'09 (Gaussian, Wallingford, CT, USA), ${ }^{14}$ with default grids and convergence criteria. Conformational searches were run with the Monte Carlo algorithm implemented in Spartan'10 using Merck molecular force field. All structures thus obtained were optimized with DFT method using first B3LYP functional and 6-31G(d) basis set, and then the same functional with $6-311+\mathrm{G}(\mathrm{d}, \mathrm{p})$ basis set. ${ }^{15}$ The above procedure afforded four minima, of which only the first two had sizable Boltzmann population $(>0.5 \%)$ at $300 \mathrm{~K}$. TDDFT calculations were run using various functionals (B3LYP, CAM-B3LYP, PBE0, M06) and basis sets (TZVP, aug-TZVP). ${ }^{15}$ The CAM-B3LYP/TZVP combination was employed for the final calculations, including 40 excited states (roots), and using the Polarizable Continuum solvent Model in its Integral Equation Formalism (IEF-PCM) for acetonitrile. ${ }^{15} \mathrm{CD}$ spectra were generated by applying a Gaussian band shape with $0.3 \mathrm{eV}$ exponential half-width, from dipole-length rotational strengths. The difference with dipole-velocity values was checked to be minimal for all relevant transitions.

\section{Biological activities}

Antimicrobial activity. The antimicrobial activity of the isolated compounds was tested against a Gram-positive bacterium (Bacillus subtilis) and a yeast fungus (Candida tropicalis) by using an agar diffusion assay according to the protocol previously described. ${ }^{16}$ Both microorganisms were grown on potatodextrose agar. Up to $100 \mu \mathrm{g}$ of each metabolite were applied per disc $(6 \mathrm{~mm}$ in diameter, Macherey-Nagel, Düren, Germany). The cultures were incubated at $30^{\circ} \mathrm{C}$ for $24 \mathrm{~h}$ before activity was determined by MIC defined as the lowest concentration of antibiotic that inhibited visible growth. ${ }^{17}$

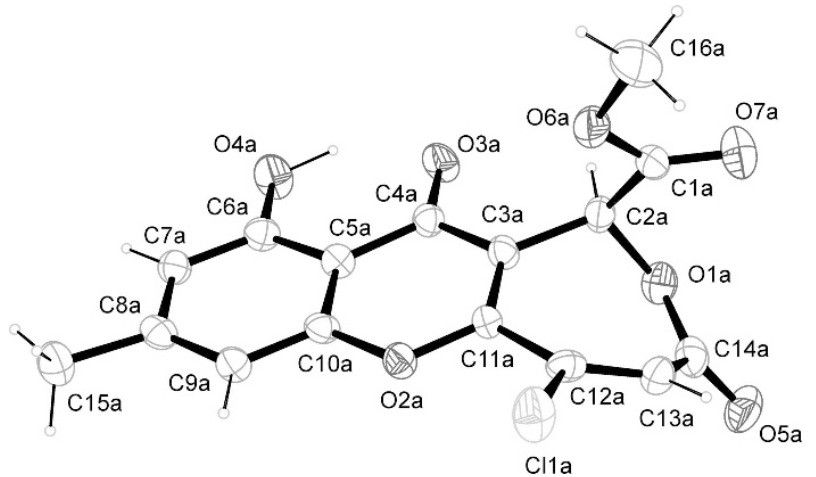

Figure 2 ORTEP view of chloromonilicin (1) showing atomic labeling. Displacement ellipsoids are drawn at the $30 \%$ probability level. Only one $(A)$ of the two crystallographically independent molecules is shown. A full color version of this figure is available at The Journal of Antibiotics journal online.
Antifungal activity. The isolates of plant pathogenic fungi (A. tenuissima, Bipolaris sorokiniana, Colletotrichum gloeosporioides and Fusarium culmorum) deposited at the Laboratory of mycology and phytopathology (All-Russian Research Institute of Plant Protection) were grown on potato-dextrose agar under near-UV light or in darkness to produce conidia. The bioassay was performed according to previously described procedures. ${ }^{18}$ Fungal conidia were washed out from media with $0.1 \%$ solution of Tween-80, adjusted to an appropriate concentration and a suspension $(900 \mu \mathrm{l})$ was added to the wells of a 24-well plates. Typically the compound $\mathbf{1}(1 \mathrm{mg})$ was dissolved in EtOH $(50 \mu \mathrm{l})$ and then water $(950 \mu \mathrm{l})$ was added. This solution was used for further dilutions in $5 \% \mathrm{EtOH}$.

Phytotoxic activity. Leaf segments of Elytrigia repens (couch-grass) $2 \mathrm{~cm}$ in length and leaf discs of $S$. arvense (perennial sow thistle) $1 \mathrm{~cm}$ in diameter were punctured with a sharp needle in the center and were treated with solution of $\mathbf{1}$ in $5 \% \mathrm{EtOH}$ at the concentration of $2 \mathrm{mg} \mathrm{ml}^{-1}$ as described previously. ${ }^{19}$ Typically, for this bioassay samples of $\mathbf{1}(400 \mu \mathrm{g})$ were dissolved in EtOH $(10 \mu \mathrm{l})$ ultrasonically, then water $(190 \mu \mathrm{l})$ was added and the samples were vortexed. At least 10 replicate leaf segments or discs were used for each treatment.

Zootoxic activity. The antibiotic $\mathbf{1}$ was evaluated on Paramecium caudatum by using the protocol already described by Rao et al. ${ }^{20}$ The assay was performed in a 24-well plate at three different concentrations of chloromonilicin (1, 10 and $100 \mu \mathrm{g} \mathrm{ml}^{-1}$ in 5\% EtOH), with three replications for each concentration. The plate was incubated at $24 \pm 1^{\circ} \mathrm{C}$. The behavior of the ciliates was observed after 3, 30 and $180 \mathrm{~min}$ post treatment using an inverted microscope.

\section{Supporting information}

${ }^{1} \mathrm{H}$ NMR and ${ }^{13} \mathrm{C}$ NMR, COSY, HSQC, HMQC, ROESY, IR and HR ESI-MS spectra for chloromonilicin are available as Supplementary Information.

\section{RESULTS AND DISCUSSION}

Chloromonilicin (1, Figure 1) was originally isolated, together with some related xanthones such as 4 -chloropinselin (2, Figure 1), from the cherry rot fungus Monilinia fructicola. ${ }^{21,22}$ Chloromonilicin was identified as a growth self-inhibitor with high antifungal activity and a novel structure of a $\beta$-chloro- $\alpha, \beta, \gamma, \delta$-unsaturated $\varepsilon$-lactone. ${ }^{21,22}$ Compound 2 appeared a probable biosynthetic precursor of chloromonilicin, while bromomonilicin and bromopinselin were prepared to test biological activity and for biosynthetic studies. ${ }^{23}$ Other biosynthetic studies for chloromonilicin were carried out by incorporation of deuterium-labeled synthetic moniliphenone and its xanthone precursor, 4-chloropinselin. ${ }^{23}$ The related chloromonilinic acids A and B were later isolated from a culture filtrate of $M$. fructicola accumulating chloromonilicin in the mycelium. ${ }^{24}$

In our work, chloromonilicin (1) was purified from the organic extract of the solid culture of $A$. sonchi as reported in detail in the Materials and Methods section. The amorphous yellow solid crystallized slowly from a mixture of benzene-methanol (3:1) giving yellow prisms. It had a molecular formula of $\mathrm{C}_{16} \mathrm{H}_{11} \mathrm{ClO}_{7}$, as deduced from its HR ESI-MS spectrum. It was identified essentially by ${ }^{1} \mathrm{H}$ and ${ }^{13} \mathrm{C}$ NMR spectra recorded in $d_{6}$-acetone (data are reported in Table 1 ). The assignments were supported by the correlations observed in the COSY, HMQC and HMBC spectra, ${ }^{10}$ and were consistent with the previously reported spectra recorded in $\mathrm{CDCl}_{3} .{ }^{21} \mathrm{With}$ respect to these latter data (assigned without the support of 2D NMR experiments), we could assign the signal of the phenolic hydroxy group hydrogenbonded with the $\mathrm{O}=\mathrm{C}-4$ as a singlet at $\delta 11.82$ in the ${ }^{1} \mathrm{H}$ NMR spectrum. Furthermore, the chemical shifts of $\delta 162.4$ and 162.1 were assigned to C-10 and C-11, which previously gave an overlapped signal in the ${ }^{13} \mathrm{C}$ NMR spectrum. Their assignments, as well as those of C-5 and $\mathrm{C}-7$, which in $\mathrm{CDCl}_{3}$ had a very close chemical shift value, were confirmed recording additional spectra in $\mathrm{C}_{6} \mathrm{D}_{6}$. In fact, in $\mathrm{C}_{6} \mathrm{D}_{6}$ they 
resonated at $\delta 155.1,154.9,108.2$ and 107.6 for C-10, C-11, C-5 and C-7, respectively.

Also the other physical (m.p. and $[\alpha]_{\mathrm{D}}$ ) and spectroscopic data (UV and IR) were very similar to those previously reported. ${ }^{21}$ Finally, the identification of $\mathbf{1}$ was supported by the data recorded by HR ESI-MS, which showed the sodiated dimeric form, the potassium and sodium clusters at $m / z 723.0232[2 \mathrm{M}+\mathrm{Na}]^{+}, 388.9805[\mathrm{M}+\mathrm{K}]^{+}$and $373.0065[\mathrm{M}+\mathrm{Na}]^{+}$, respectively.

The identification of chloromonilicin was confirmed by the X-ray analysis of suitable crystals obtained as yellow prisms and the molecular structure is reported in Figure 2. Compound $\mathbf{1}$ crystallizes in the hexagonal $\mathrm{P}_{5}$ space group with two independent molecules in the asymmetric unit. The two independent molecules (named A and B) are very similar to each other. Since minimal differences were found in the geometrical parameters, only molecule A is shown in Figure 2.

The molecule skeleton of compound 1 consists of three rings that correspond to a chromen-4-one ring system fused to an oxepin-2 $(3 \mathrm{H})$-one ring. All bond lengths and angles are in the normal range and suggest a high degree of conjugation in the molecule. Bond distances and geometry of the two six-membered fused rings confirm the presence of a chromen-4-one moiety that displays an intramolecular $\mathrm{OH}-\mathrm{O}$ hydrogen bond. The C-3-C-11 and C-12-C-13 bond lengths [1.354(7) and 1.322(8) $\AA$ for molecule A; 1.345(7) and 1.319 (8) $\AA$ for molecule B] confirm the nature of the two $\mathrm{C}=\mathrm{C}$ double bonds in the seven-membered ring. The molecule of chloromonilicin (1) is characterized by a high rigidity. The two six-membered fused rings are planar, while the oxepin-2 $(3 \mathrm{H})$-one ring assumes a boat conformation similar to that of $1,3,5$-cycloheptatriene, ${ }^{25}$ with the carboxymethyl group occupying an axial position and $\mathrm{H}-2$ hydrogen

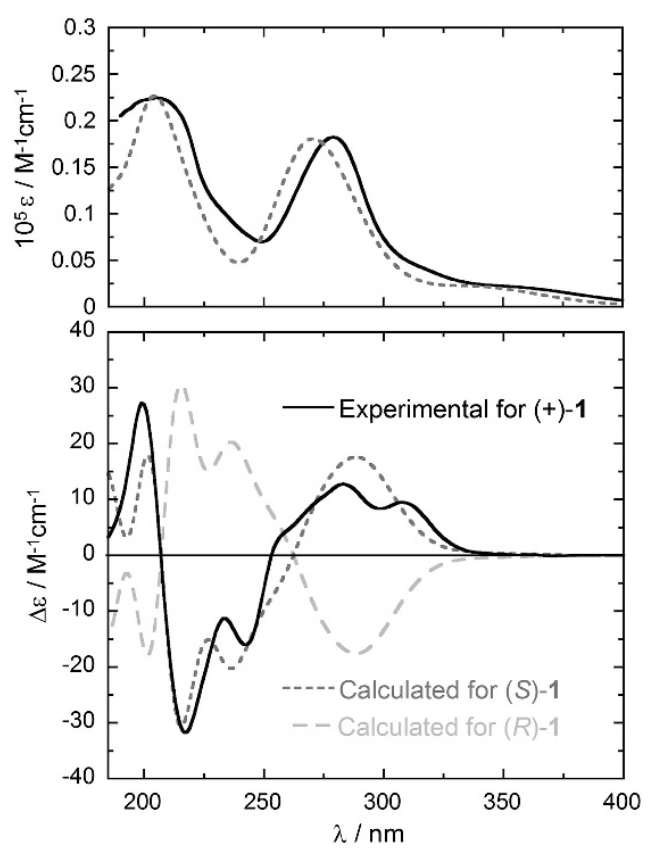

Figure 3 UV-vis absorption (top) and ECD spectra (bottom) of (+)-1 measured in acetonitrile (solid lines, $4.25 \mathrm{~mm}, 0.01 \mathrm{~cm}$ cell) compared with spectra calculated for $(R)-1$ and (S)-1 with TDDFT at CAM-B3LYP/TZVP// $B 3 L Y P / 6-311+G(d, p)$ level as Boltzmann average of two conformers at $300 \mathrm{~K}$ (dotted lines). Calculated spectra were obtained as sums of Gaussian bands with $0.3 \mathrm{eV}$ exponential half-width, red-shifted by $18 \mathrm{~nm}$ and scaled by a factor 0.5 . an equatorial one. A unique stereogenic center is present in the molecule at C-2 atom. Owing to the strong anomalous scattering of chlorine atoms, it was possible to assign the absolute configuration from X-ray data. In both the two independent molecules the absolute configuration at C-2 was established as $(S)$ by anomalous dispersion effects.

The absolute configuration of (+)-(S)-1, established by X-ray analysis, was confirmed by means of ECD spectroscopy. The UV-vis absorption and ECD spectra of (+)-1 measured in acetonitrile are shown in Figure 3. They feature several bands in the $185-350 \mathrm{~nm}$ region, due to the various transitions of the extended conjugated chromophore. The ECD spectrum of (+)-1 was then calculated with TDDFT $^{26}$ using the geometries obtained by a consolidated computational procedure. ${ }^{27}$ This latter consists of a preliminary conformational search with molecular mechanics (Merck molecular force field) using a Monte Carlo algorithm, followed by DFT geometry optimizations; the details are described in the Computational section. As a result, only two low-energy conformers populated at $300 \mathrm{~K}$ were obtained for chloromonilicin, because of the relatively rigid cyclic skeleton. The lowest-energy conformer found by B3LYP/6-311+G(d,p) optimizations, depicted in Figure 4, accounts for $70 \%$ population at $300 \mathrm{~K}$ and it is almost coincident with the X-ray structure (the root-mean square deviation between the two structures for non-hydrogen atoms is $0.23 \AA$ ). The second conformer (relative energy $+0.50 \mathrm{kcal} \mathrm{mol}^{-1}$,

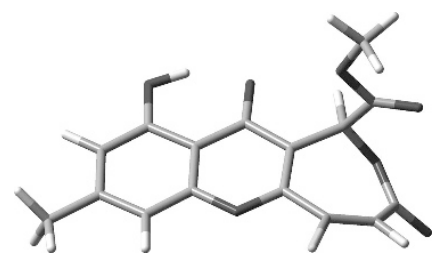

Figure 4 Lowest-energy B3LYP/6-311+G(d,p) structure of (S)-1. A full color version of this figure is available at The Journal of Antibiotics journal online.

Table 2 Effect of the concentration of chloromonilicin on growth inhibition (zone of lysis, $\mathrm{mm}$ ) of five microorganisms

\begin{tabular}{lcccc}
\hline & \multicolumn{4}{c}{$\mu g$ Per disc } \\
\cline { 2 - 5 } Microorganism & 0.5 & 1.0 & 2.5 & 5.0 \\
\hline Escherichia coli & $3 \pm 0$ & $4.5 \pm 0.5$ & $5.5 \pm 0.5$ & $6 \pm 0$ \\
Pseudomonas fluorescens & $4.5 \pm 0.5$ & $5.5 \pm 0.5$ & $7 \pm 0$ & $7.5 \pm 0.5$ \\
Bacillus subtilis & $7 \pm 0$ & $9.5 \pm 0.5$ & $11 \pm 0$ & $12.5 \pm 0.5$ \\
Paenibacillus polymyxa & 0 & $1 \pm 0$ & $2 \pm 0$ & $2 \pm 0$ \\
Candida tropicalis & $0.5 \pm 0.5$ & $1.5 \pm 0.5$ & $3 \pm 0$ & $4 \pm 0$ \\
\hline
\end{tabular}

Table 3 Effect of the concentration of chloromonilicin on percentage of germinated conidia of four phytopathogenic fungi

\begin{tabular}{lcccc}
\hline & \multicolumn{5}{c}{$\mu g \mathrm{ml}^{-1}$} \\
\cline { 2 - 5 } Fungal specie & 0 & 1 & 10 & 100 \\
\hline Fusarium culmorum & $100 \pm 0$ & $58.7 \pm 12.5$ & 0 & 0 \\
Bipolaris sorokiniana & $87.5 \pm 3.5$ & $55.1 \pm 12.9$ & 0 & 0 \\
Colletotrichum gloeosporioides & $67.3 \pm 2.2$ & 0 & 0 & 0 \\
Alternaria tenuissima & $91.9 \pm 1.5$ & $79.1 \pm 2.4$ & $12.1 \pm 1.9$ & $4.7 \pm 0.4$
\end{tabular}


$30 \%$ population) differs from the absolute minimum only in the rotamerism around the $\mathrm{C}-1-\mathrm{C}-2$ bond. The axial arrangement of the carboxymethyl group minimizes the electrostatic repulsion between the carboxymethyl and ketone moieties. ECD spectra were calculated on the two conformers with TDDFT method using various combinations of functionals and basis sets (see Computational section). In all cases, the spectra calculated for the two conformers were very similar. The Boltzmann-weighted spectra computed for both enantiomers of 1 at CAM-B3LYP/TZVP level of theory, and including a solvent model for acetonitrile, are shown in Figure 3. The good agreement observed between the calculated spectrum for $(S)-\mathbf{1}$ and the experimental spectrum allowed us to definitely establish the absolute configuration of chloromonilicin as $(+)-(S)-1$.

Chloromonilicin showed a wide spectrum of antimicrobial activity against bacteria, yeast and plant pathogenic fungi. When the compound was assayed by paper disc technique, the MIC against Ba. subtilis, Escherichia coli and Pseudomonas fluorescens was lower than $0.5 \mu \mathrm{g}$ per disc (Table 2). Other two microorganisms tested (Paenibacillus polymyxa and $\mathrm{Ca}$. tropicalis) were less sensitive to chloromonilicin with MIC about $1 \mu \mathrm{g}$ per disc (Table 2). Chloromonilicin demonstrated ability to inhibit germination of conidia of four widely distributed plant pathogenic fungi, namely, A. tenuissima, Bi. sorokiniana, Co. gloeosporioides and F. culmorum, with $\mathrm{MIC}<1 \mu \mathrm{g} \mathrm{ml}^{-1}$ (Table 3).

Chloromonilicin was tested for its phytotoxic activity on punctured leaf discs of perennial sow thistle and leaf segments of couch-grass and no activity of this compound was found even at the highest concentration of $2 \mathrm{mg} \mathrm{ml}^{-1}$ used in this study.

At the minimal concentration of $1 \mu \mathrm{g} \mathrm{ml}^{-1}$ the antibiotic 1 fully inhibited the movement of Par. caudatum after $1 \mathrm{~h}$ post treatment. At the higher concentrations of chloromonilicin $\left(10\right.$ and $100 \mu \mathrm{g} \mathrm{ml}^{-1}$ ) the ciliates were dead after 20 and $10 \mathrm{~min}$ of incubation, respectively. So, although the antibiotic did not demonstrate acute toxicity, at the lowest concentration it remained still active against Par. caudatum.

In an earlier study of Sassa et al., ${ }^{21}$ where they used agar dilution method on glucose nutrient agar, chloromonilicin showed marked antifungal activity against the human pathogenic fungi Candida albicans and Trichophyton spp. (1.5-6.2 $\left.\mu \mathrm{g} \mathrm{ml}^{-1}\right)$, while a number of tested bacteria were almost insensitive to the antibiotic $\left(\mathrm{MIC} \geqslant 50 \mu \mathrm{g} \mathrm{ml}^{-1}\right)$. Chloromonilicin possessed also hyphal growthinhibiting activity against its producing fungus, $M$. fructicola at $5 \mu \mathrm{g}$ per disc. ${ }^{21}$ The differences in the results on the antibacterial activity of $\mathbf{1}$ in the above mentioned study and in our research can be explained with the different bioassays techniques used as well as the different sensitivity of bacteria to this antibiotic.

In this study, we also demonstrated the absence of phytotoxic activity of chloromonilicin on leaves of two plants and high activity against some plant pathogenic fungi. Possibly, this metabolite is a defense factor of $A$. sonch $i$ against antagonistic microorganisms. From a practical point of view chloromonilicin can potentially be used as a natural non-phytotoxic fungicide to protect crops from fungal diseases. However, toxicological studies of chloromonilicin as well as its producing organism are necessary because of the toxic effect of this compound on Par. caudatum. Future studies are needed to enlarge the production of the antibiotic and evaluate its in vivo conditions. The former step might be reached by media and strain selection, optimization of culture conditions and of compound isolation and purification processes.

In conclusion, chloromonilicin was isolated for the first time as the main antimicrobial metabolite produced by $A$. sonchi. This was the occasion to assign its absolute configuration, not reported before, and to extensively investigate its biological activity. The results obtained pushed us to plan a scale-up production of this promising antimicrobial metabolite to test it in in vivo experiments. However, additional toxicology studies should be carried out to confirm the potential of chloromonilicin for practical application as antimicrobial agent in agriculture and/or medicine.

\section{ACKNOWLEDGEMENTS}

We thank Mr L Chistyi and Dr V Zakharov (Research Institute of Hygiene, Occupational Pathology and Human Ecology, Federal Medical Biological Agency, St Petersburg, Russian Federation) for NMR and Dr A Rudenko (Institute of Toxicology, Federal Medical Biology Agency, Saint-Petersburg, Russian Federation) for HR ESIMS spectra. The research work of the Russian group on production, isolation and biological characterization of bioactive metabolites produced by plant pathogens was supported by Russian Fund of Basic Research (project N 12-04-00853). This research was carried out in part in the frame of Programme STAR, financially supported by UniNA and Compagnia di San Paolo. AE is associated with the Istituto di Chimica Biomolecolare del CNR, Pozzuoli, Italy.

1 Donald, W. W. Management and control of Canada thistle (Cirsium arvense). Rev. Weed Sci. 5, 193-250 (1990)

2 Evans, H. C. in Biological Control of Weeds with Fungi. The Mycota, Vol. 11, 145-172 (Springer-Verlag, Berlin Heidelberg, 2013).

3 Cimmino, A. et al. Abstracts of Papers 8th PSE (The Phytochemical Society of Europe) Meeting on Biopesticides, La Palma, Canary Islands, Spain, 2009.

4 Vurro, M. in Novel Biotechnologies for Biocontrol Agent Enhancement and Management (eds Vurro, M. \& Gressel, J.), Ch. 3, 53-74 (Springer, Netherlands, 2007).

5 Cimmino, A., Andolfi, A., Berestetskiy, A. \& Evidente, A. Production of phytotoxins by Phoma exigua var. exigua, a potential mycoherbicide against perennial thistles. J. Agric. Food Chem. 56, 6304-6309 (2008).

6 Berestetskiy, A. O. \& Kurlenya, A. S. Antimicrobial properties of some phytopathogenic micromycetes. Mikologia Fitopatologia 48, 123-134 (2014).

7 Evidente, A., Punzo, B., Andolfi, A., Berestetskiy, A. \& Motta, A. Alternethanoxin A and B, polyciclic ethanones produced by Alternaria sonchi, potential mycoherbicides for Sonchus arvenis biocontrol. J. Agric. Food Chem. 57, 6656-6660 (2009).

8 Berestetskiy, A. et al. Alternethanoxins C-E, further polycyclic ethanones produced by Alternaria sonchi, a potential mycoherbicide for Sonchus arvensis biocontrol. J. Agric. Food Chem. 63, 1196-1199 (2015).

9 Bury, M. et al. Evaluation of the anticancer activities of two fungal polycyclic ethanones, alternethanoxins $\mathrm{A}$ and $\mathrm{B}$, and two of their derivatives. Int. J. Oncol. 38, 227-232 (2011).

10 Berger, S. \& Braun, S. 200 and More Basic NMR Experiments: A Practical Course (Wiley-VCH, Weinheim, 2004).

11 Altomare, A. et al. A new tool for crystal structure determination and refinement. J. Appl. Crystallography. 32, 115-119 (1999).

12 Sheldrick, G. M. A short history of SHELX. Acta Crystallogr. A64, 112-122 (2008).

13 Flack, H. D. On enantiomorph-polarity estimation. Acta Crystallogr. A39, 876-881 (1983).

14 Frisch, M. J. et al. Gaussian'09, Revision D.01, (Gaussian, Inc., Wallingford, CT, 2013).

15 All references about DFT functionals, basis sets and solvent models can be found in the on-line documentation for Gaussian'09 at www.gaussian.com/g_tech/g_ur/g09help. $\mathrm{htm}$.

16 Bottalico, A., Capasso, R., Evidente, A., Randazzo, G. \& Vurro, M. Cytochalasins: structure-activity relationships. Phytochemistry 29, 93-96 (1990).

17 Onishi, H. R. et al. Antibacterial agents that inhibit lipid A biosynthesis. Science 274, 980-982 (1996).

18 Talontsi, F. M. et al. Zoosporicidal metabolites from an endophytic fungus Cryptosporiopsis sp. of Zanthoxylum leprieurii. Phytochemistry 83, 87-94 (2012).

19 Berestetskii, A. O. et al. Isolation, identification, and characteristics of the phytotoxin produced by the fungus Alternaria cirsinoxia. App. Biochem. Microbiol. 46, 75-79 (2010)

20 Rao, J. V., Srikanth, K., Arepalli, S. K. \& Gunda, V. G. Toxic effects of acephate on Paramecium caudatum with special emphasis on morphology, behaviour, and generation time. Pestic. Biochem. Phys. 86, 131-137 (2006).

21 Sassa, T., Kachi, H. \& Nukina, M. Chloromonilicin, a new antifungal metabolite produced by Monilinia fructicola. J. Antibiot. (Tokyo) 38, 439-441 (1985).

22 Kachi, H., Hattori, H. \& Sassa, T. A new antifungal substance, bromomonilicin, and its precursor produced by Monilinia fructicola. J. Antibiot. (Tokyo) 39, 164-166 (1986).

$23 \mathrm{Kachi}, \mathrm{H}$. \& Sassa, T. Isolation of monilphenone, a key intermediate in xanthone biosynthesis from Monilinia fructicola. Agric. Biol. Chem. 50, 1669-1671 (1986). 
24 Sassa, T., Horiguchi, K. \& Suzuki, Y. Chloromonilinic acids A and B, novel catabolites of the growth self-inhibitor chloromonilicin isolated from Monilinia fructicola. Agric. Biol Chem. 53, 1337-1341 (1989).

25 Traetteberger, $\mathbf{M}$. The molecular structure of 1,3,5-cycloheptatriene in the vapor phase as determined by the sector electron diffraction method. J. Am. Chem. Soc. 86, 4265-4270.
26 Autschbach, J. Computing chiroptical properties with first-principles theoretical methods: Background and illustrative examples. Chirality 21, E116-E152 (2009).

27 Pescitelli, G., Di Bari, L. \& Berova, N. Conformational aspects in the studies of organic compounds by electronic circular dichroism. Chem. Soc. Rev. 40, 4603-4625 (2011).

Supplementary Information accompanies the paper on The Journal of Antibiotics website (http://www.nature.com/ja) 